\title{
Short-term effects of compost amendments to soil on soil structure, hydraulic properties, and water regime
}

\author{
Pierre-Adrien Rivier ${ }^{1}$, Dorina Jamniczky ${ }^{2}$, Attila Nemes ${ }^{1}$, András Makó ${ }^{3}$, Gyöngyi Barna ${ }^{3}$, \\ Nikolett Uzinger ${ }^{3}$, Márk Rékási ${ }^{3}$, Csilla Farkas ${ }^{1,3^{*}}$ \\ ${ }^{1}$ NIBIO, Norwegian Institute of Bioeconomy Research, Oluf Thesens vei 43, 1433, Aas, Norway. \\ ${ }^{2}$ University of Milan, Via Festa del Perdono 7, 20122 Milano MI, Italy. \\ ${ }^{3}$ Institute for Soil Sciences, Centre for Agricultural Research of the Eötvös Loránd Research Network, H-1022 Budapest, Herman Ottó út \\ 15 , Hungary. \\ *Corresponding author. E-mail: csilla.farkas@nibio.no
}

\begin{abstract}
Despite the increasing interest in applying composts as soil amendments worldwide, there is a lack of knowledge on short-term effects of compost amendments on soil structural and hydraulic properties. Our goal was to study the effect of compost and vermicompost-based soil amendments on soil structure, soil water retention characteristics, aggregate stability and plant water use efficiency compared to that of mineral fertilizers and food-waste digestate and examine if these effects are evident within a short time after application. We set up a pot experiment with spring wheat using a sandy and a loamy soil receiving either mineral fertilizer (MF); dewatered digestate from anaerobic digestion of food waste (DG), vermicomposted digestate (VC_DG); sewage sludge-based compost (C_SS) and sewage sludge-based vermicompost (VC_SS). We then monitored and calculated the soil water balance components (irrigation, outflow, evaporation, transpiration, and soil water content). At harvest, we measured shoot biomass, soil texture, bulk density, water retention characteristics and aggregate stability. The irrigation use efficiency (IE) and the plant water use efficiency (WUE) were calculated for each treatment by dividing the transpiration and the dry shoot biomass with the amount of water used for irrigation, respectively. For the sandy soil, we used X-Ray computed tomography to visualise the pore system after applying organic amendments and to derive metrics of the pore-network such as its fractal dimension, imaged macroporosity and critical pore diameter. X-Ray tomography indicated that composting and vermicomposting resulted in more complex and diverse porous system and increased soil macroporosity. The increased fractal dimensions also indicated that compost and vermicompost can contribute to structure formation and stabilization within a short time after their application. Despite the small application rate and short incubation time, the application of organic amendments to the two different soil types resulted in improved soil water holding capacity and water use efficiency. Composting and vermicomposting appeared to have the best effect at reducing the irrigation demand and evaporation losses and increasing the water use efficiency of the plant, likely through their effect on soil structure and the pore-size distribution.
\end{abstract}

Keywords: Compost; Vermicompost; Soil water retention; Aggregate stability; Water use efficiency; X-CT imaging.

\section{INTRODUCTION}

Intensification of soil management due to increased food demand has led to degradation of soil resources all over the world (Pierzynski and Brajendra, 2017; Stolte et al., 2016), and global food demand will probably be an immense challenge for humanity in the future (Pravalie, 2021). Smith et al. (2016) emphasised cropping practices and livestock management as the main causes of soil physical degradation and reduction in soil fertility and soil resilience. According to Turpin et al. (2017), in many European countries the main soil threats concern soil erosion (Borelli et al., 2020); soil organic matter decline (Obalum et al., 2017), soil structural degradation, loss of soil structural stability (Virto et al., 2015) and decline in soil biodiversity (Tibbet et al., 2020). This leads to a reduced capacity of the soil to infiltrate and retain water and nutrients, and reduced resilience to various forms of erosion in the landscape (Holman et al., 2003). Soil compaction and reduced water retention of soils leads to the intensification of flash floods (Alaoui et al., 2018) and soil loss due to water erosion, as well as to increased loads of particles, nutrients, and pollutants to watercourses (Waltner et al., 2018; Zhao et al., 2018). Thus, maintaining or even restoring soil structure and stability is essential for ensuring healthy terrestrial and freshwater ecosystem functioning.

Traditionally used mineral fertilisers are sources of nutrients, but they don't function as soil conditioners and, in some cases, may deteriorate soil structure (Lee et al., 2009; Massah and Azadegan, 2016; Roba, 2018). Moreover, mineral fertilizers are obtained by mining, processing, and transporting valuable natural resources; thus, their application does not meet the conditions of circular economy.

Organic by-products contain valuable raw materials and energy that constitute wasted natural resources when discarded (Unnisa and Rav, 2012). Thus, safe, sustainable use of organic waste materials and their valorisation is a global issue. Several technologies have been developed to recycle organic waste, like composting, biogas and algae production and land treatment of sludge/wastewater, each having their own benefits and limitations (Polprasert, 1989; Ruggieri et al., 2008). According to Tejada and Gonzalez (2006), composts have a better effect on soil quality compared to other organic waste-based soil amendments, as they improve soil structural stability (Owen et al., 2021), soil fertility and productivity (Jindo et al., 2016), 
increase soil water retention, infiltration capacity (Maylavarapu and Zinati, 2009; Whelan et al., 2013) and crop properties (Jiang et al., 2021), and have been successfully applied in soil restoration (Beck-Broichsitter, 2018; Tejada et al., 2009). Studies related to compost application focus, predominantly, on seasonal (Leelamanie and Manawardana, 2019) or long-term (Adugna, 2016; Gaiotti et al., 2017; Ros et al., 2006) changes in soil hydro-physical properties and nutrient dynamics after compost application. The concise review of Kranz et al. (2020) on the effects of compost incorporation on physical properties of urban soils refers to more than 15 studies each having a timestep from 1 to 12 years. Little attention is given to possible short-term changes in soil structure and on how composting influences the water regime of the soil-plant system.

Despite the increasing interest in applying composts as soil amendments worldwide (Martinez-Blanco et al., 2013), there is a lack of knowledge on the degree to which compost amendments affect soil structural and hydraulic properties (Whelan et al., 2013). Most publications on compost application focus on nutrient availability, plant development, contaminants, and food safety. A search in the scientific literature showed that out of 600 articles published on these topics during the last 11 years, $71 \%$ was related to nutrient content and their availability in the compost. Only some $10 \%$ of the studies consider soil structure and hydraulic properties of compost-amended soils. Changes induced by the application of composted amendments in soil water regime are discussed in $3 \%$ of those studies published.

Soil structure governs the storage and transport of water and nutrients and heat regimes (Horel et al., 2019), and thus determines crop and vegetation performance (Miedema, 1997). Composted organic matter has direct and indirect effects on soil structure (Cahyono et al., 2020; Ghezzehei, 2012; Kranz et al., 2020; Or et al., 2021). Composting improves soil structure by the binding between organic matter and clay particles via cation bridges (direct effect) and through stimulation of microbial activity and root growth (Farrell and Jones, 2009; Gao et al., 2010). Cambardella et al. (2003) found that organic substrates that did not degrade during the composting process can readily mineralise after incorporation in soil, which underlines the importance of studying short term effects of composting on soil structure.

Soil structure can be characterised directly and indirectly. The soil hydraulic functions (soil water retention curve and hydraulic conductivity function) are indirect indicators of soil structure. Visualisation of the pore system (e.g., X-Ray computed tomography of undisturbed soil samples) is a direct, but costly technique to evaluate soil structure (Koestel et al., 2018). Among other soil structure characterisation methods, aggregate stability measurements facilitate the determination of the effects of various factors that impact soil structure and its persistence (Horel et al., 2019). The combined sieve-pipette method is used routinely to assess micro-aggregate stability (Bieganowski et al., 2010), however, it cannot be used reliably for soils with high organic matter content. At present, the laser diffraction method (LDM) is not commonly used to determine aggregate stability (Amézketa et al., 2003; Kubinova et al., 2021; Mukherjee and Lal, 2013), therefore the LDM is a relatively new option to investigate soils with organic amendments.

Although studies have investigated the changes in soil structural properties as a result of compost and other soil amendments application, most of them are focusing on long-term changes in soil structure and on selected soil properties. The present study examines many of these characteristics in an integrated way, focusing on the rapid, short-term effects of organic amendments on soil water balance components and plant water use efficiency.

Given the lack of critical attention paid to the effects of composting on soil structure and water regime, the aim of this study was to examine the short-term effects of compost and vermicompost-based soil amendments on soil structure, soil water retention characteristics, aggregate stability and plant water use efficiency compared to that of mineral fertilizer and food-waste digestate.

We hypothesise that composts promote soil structure formation more than mineral fertilizers and food-waste digestates do, leading to improved soil structural status and water regime, and that these effects are evident within a relatively short time after compost application.

\section{MATERIALS AND METHODS 2.1 Experimental setup}

We used two contrasting soil types in our experiments, a light sandy soil (Lamellic Arenosol) and a loamy clay soil (Calcic Chernozem; WRB, 2014), collected from the upper 20 $\mathrm{cm}$ layer of agricultural fields near Nyíregyháza $\left(21^{\circ} 24^{\prime} 36.01\right.$ E, $\left.47^{\circ} 57^{\prime} 47.94 \mathrm{~N}\right)$ and Tiszavasvári $\left(21^{\circ} 34^{\prime} 08.57 \mathrm{E}\right.$, $\left.47^{\circ} 59^{\prime} 13.71 \mathrm{~N}\right)$ in Hungary, respectively. The soils were airdried, crushed, and homogenised to discard plant residues and stones. The properties of both soils are given in Table 1 and further described in Foereid et al. (2019).

The pot experiment was set up under controlled conditions in a greenhouse (Figure 1). The organic soil amendments were carefully mixed with the soil at a rate equivalent to $20 \mathrm{t} \mathrm{ha}^{-1}$ (i.e., $2 \%$ of soil dry weight), which is within the range of common application rates of organic amendments for crop production (ECN, 2017). Both soils received either of the following amendments: mineral fertilizer only (MF); dewatered digestate from anaerobic digestion of food waste (DG), the digestate of the DG treatments subjected to vermicomposting (VC_DG) (for details on production, see Jamniczky, 2018); sewage sludgebased compost (co-composted sewage sludge and green waste in a ratio of 3:1 wet weight, C_SS) and sewage sludge-based vermicompost (VC_SS) (for details on production, see Rékási et al., 2019).

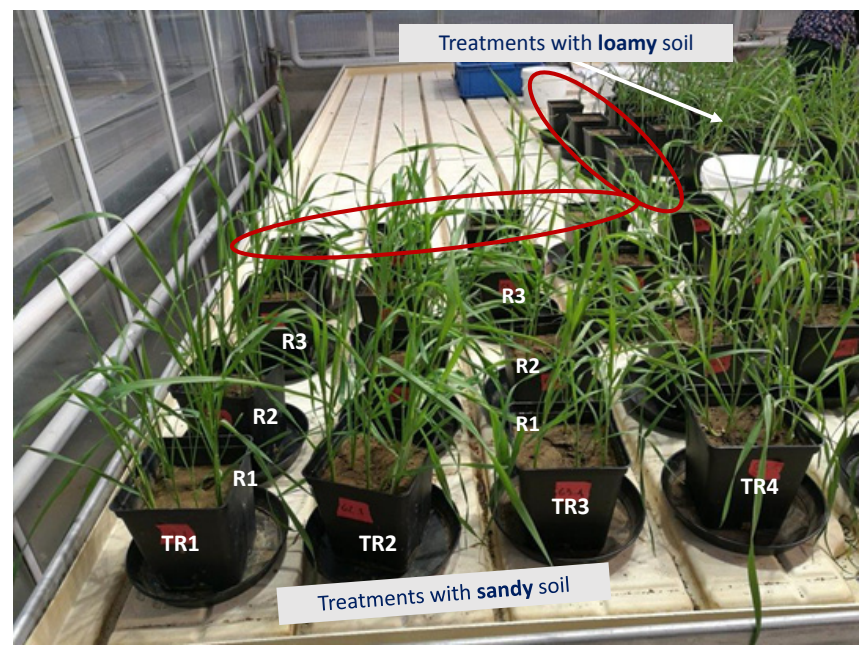

Fig. 1. The experimental set-up in the greenhouse; TR refers for treatment, R refers for replicate and the red circles show the treatments without crop. 
The mixes were placed in $1 \mathrm{~L}$ pots. The bulk density of the amended soils and their initial water content were determined before saturating the soil with water. The soil water content corresponding to maximum water holding capacity (WHC) was determined as described by Wilke (2005). Spring wheat was sown in three replicate pots per treatment (thinned to 10 plants after seedling emergence), and a fourth pot without plants was included to measure evaporation from bare soil. Depending on the water consumption, the pots were watered every second or third day to water holding capacity for 30 days.

\subsection{Determination of the water balance components and the plant water use efficiency}

Soil water balance components were monitored and calculated by i) weighting the pots before watering to record actual soil water content; ii) registering the irrigation amount; iii) measuring the outflow; iv) weighting the pots without crop to quantify the evaporation from the bare soil surface. The transpiration (or root water uptake) was calculated for each pot and each irrigation period, using the soil water balance equation:

$T R=I-O-E-\Delta \theta$

where TR is the transpiration $(\mathrm{mL}) ; I$ is the irrigation $(\mathrm{mL}) ; O$ is the outflow $(\mathrm{mL}) ; E$ is the evaporation $(\mathrm{mL})$ and $\Delta \theta$ is the change in the soil water content between two scheduled irrigation times $(\mathrm{mL})$.

At the end of the pot experiment, soil samples (disturbed; $\mathrm{n}=6$, meaning two samples per replicate; undisturbed; $\mathrm{n}=2$ ) were collected for analyses. The shoot biomass was collected, dried, and measured.

We calculated the water use efficiency (WUE, in $\mathrm{kg}$ of shoot dry weight per $\mathrm{m}^{3}$ of water) as transformation efficiency of water into dry biomass by dividing the dry shoot biomass with the total amount of water used for irrigation, according to the formula (De Pascale et al., 2011):

$$
W U E=\frac{\text { dry biomass }}{\text { water used for producing biomass }} \text {, }
$$

in our case $\quad W U E=\frac{\text { dry shoot weight }}{\text { irrigation water }}$

\subsection{Determination of soil texture and structural properties}

Soil texture and aggregate stability measurements were performed in two repeated measurements per replicate $(n=2 \times 3)$ from disturbed soil samples. Micro-aggregate stability (MiAS, $\%$ ) was assessed according to Vageler's structure factor from the rate of the clay fractions determined with dispersion $\left(C_{d}\right)$ and without $\left(C_{n d}\right)$ dispersion (Vageler, 1932):

$$
M i A S=100 * \frac{C_{d}-C_{n d}}{C_{d}}
$$

The amount of sand, silt and clay was measured by the laser diffraction method. Prior to the particle-size analysis, the dry soil samples were moistened by dropwise addition of standard Calgon dispersant (solution of sodium hexametaphosphate and sodium carbonate) on a watch glass, which was thereafter washed into the $\sim 800 \mathrm{~cm}^{3}$ tank of the dispersion unit. Further Calgon solution was added to the deionized water + soil suspension and the complete disaggregation and dispersion was then provided by ultrasound treatment. For the non-dispersed treatment used to determine MiAS, we used neither ultrasound applications nor chemical compounds; the samples were only

Table 1. Chemical and physical characteristics of the soils, measured using standard methods by Eurofins Environment Testing Norway

\begin{tabular}{|c|c|c|c|}
\hline Soil properties & Unit & Sandy soil & Loamy soil \\
\hline \multicolumn{4}{|c|}{ Physical and chemical properties } \\
\hline Dry matter & $\%$ & 99.4 & 96.9 \\
\hline $\mathbf{p H}_{\mathrm{H} 2 \mathrm{O}}$ & & 7.0 & 6.4 \\
\hline EC & $\mathrm{mS} \mathrm{m}^{-1}$ & 2.5 & 5.4 \\
\hline Loss of ignition & $\%$ & 1.2 & 5.7 \\
\hline \multicolumn{4}{|c|}{ Elements for plant growth, total } \\
\hline Total carbon & $\%$ & 0.22 & 1.90 \\
\hline Total nitrogen & $\%$ & 0.04 & 0.21 \\
\hline Phosphorus & $\%$ & 0.023 & 0.071 \\
\hline Potassium & $\%$ & 0.07 & 0.31 \\
\hline Calcium & $\%$ & 0.09 & 0.36 \\
\hline Magnesium & $\%$ & 0.12 & 0.36 \\
\hline Sulfur & $\mathrm{mg} \mathrm{kg}^{-1}$ & 49 & 210 \\
\hline \multicolumn{4}{|l|}{ Available nutrients } \\
\hline Ammonium-N & $\%$ & 0.0008 & 0.0019 \\
\hline Nitrate-N & $\%$ & 0.0003 & 0.0032 \\
\hline Phosphorus & $\%$ & 0.0047 & 0.0100 \\
\hline Potassium & $\%$ & 0.010 & 0.036 \\
\hline Calcium & $\%$ & 0.11 & 0.3100 \\
\hline Magnesium & $\%$ & 0.008 & 0.033 \\
\hline
\end{tabular}
AS (Foereid et al., 2019). 
shaken in water prior to determining the amount of water-stable aggregates. We measured the amount of the clay fraction by LDM using a Malvern Mastersizer 2000 device (Malvern Panalytical Ltd, Malvern, UK) with a HydroG dispersion unit (refraction index: 1.52; absorption index of 0.1 for the dispersed phase, and a refraction index of 1.33 for water as the dispersing phase) as described by Horel et al. (2019). The obscuration values were between 10 and $20 \%$, as recommended in the manual of the Mastersizer 2000. Macro-aggregate stability (MaAS, $\%$ ) was first measured using a traditional wet sieving apparatus (Eijkelkamp, Soil and Water, Giesbeek, The Netherlands), using $4 \mathrm{~g}$ of soil per sample of 1-2 mm size aggregates (Kemper and Rosenau, 1986).

However, our preliminary experiments showed that this method is not suitable for measuring the macroaggregate stability of sandy soils, as a large amount of soil would be needed to extract representative amount of 1-2 $\mathrm{mm}$ large aggregates. The small amount of extracted aggregates was not representative for the whole soil sample, because the organic and non-organic colloids concentrated in the aggregates. Therefore, the $M a A S$ was determined from the records of the abovedescribed laser diffraction method using the following equation:

$M a A S=100 * \frac{F 250_{n d}-F 250_{d}}{100-F 250_{d}}$

where $F 250_{n d}$ and $F 250_{d}$ (in vol\%) stand for fraction of particles larger than 250 micrometers of non-dispersed and dispersed soil samples, respectively.

\subsection{Determination of soil water retention characteristics}

We collected duplicate undisturbed soil cores $\left(100 \mathrm{~cm}^{3}\right.$ in volume and $37 \mathrm{~mm}$ in height) from each treatment and determined their bulk density (BD) and soil water retention characteristics (WRC). Soil water retention was determined at five matric potentials. We used the $100 \mathrm{~cm}^{3}$ soil cores covered by a porous cloth at the bottom to measure WRC at matric potentials of $-10,-50$ and $-100 \mathrm{hPa}$, using a sandbox apparatus (Eijkelkamp, 2019). The samples were subsequently placed in a pressure plate apparatus (Klute, 1986) and equilibrated at matric potentials of -300 and $-1000 \mathrm{hPa}$ for 34 and 42 days, respectively. The unusually long equilibration time was advised by Angyal (2019). We left the porous cloth on the samples for the pressure plate measurements and did not use any other material to enhance contact between the samples and the ceramic plate.

\subsection{X-Ray computed tomography imaging of undisturbed soil cores from treatments with sandy soil}

X-Ray computed tomography (from here on X-CT) imaging of undisturbed soil columns is the most advanced direct, nondestructive, and non-invasive method today to help visualize soil structure and pore-size distribution (Schneider et al., 2012; Taina et al., 2007). From indirect analyses of soil structure (e.g., aggregate stability, water retention curve etc.) it is difficult to decide, whether the detected changes, compared to the control (MF), occur only because we mix the soil with structured materials of high organic matter content that behave as a separate medium, or partly also because some structural development occurred within short time after amendment application. Hence, X-CT imaging is a direct useful tool for testing our original hypothesis.
Since X-CT scanning is a highly expensive technology, it was carried out for the poorly structured sandy soil only, separately from the pot experiments. The soil was mixed with the different amendments according to the chosen application rate ( $2 \%$ of soil dry weight). After mixing, we watered the treatments to WHC twice and let them dry until equilibrated. After two weeks of watering-drying cycles, we collected undisturbed soil samples. Soil samples were taken in aluminium cylinders of $6.53 \mathrm{~cm}$ diameter and $6.00 \mathrm{~cm}$ height, yielding a volume of about $200 \mathrm{~cm}^{3}$. The samples were scanned in a high-end tool for 3D industrial and scientific X-CT analysis (GE Phoenix v|tome|x $\mathrm{m}$ ) at the Swedish University of Agricultural Sciences (SLU) in Uppsala, with a voxel size of 40 $\mu \mathrm{m}$. The technical details are described in Koestel et al. (2018). Two thousand radiographs were obtained for each soil sample. These radiographs were reconstructed using the software package GE datos $\mid \mathrm{x}$ (GE, 2014). Further image processing was achieved using the SoilJ plugin (Koestel, 2017) of ImageJ/FIJI free software (Shindelin et al., 2012), the BoneJ plugin for PoreSpazeAnalyzer (Daube et al., 2010) and a high-end imageprocessing computer at NIBIO, Norway. This approach allows image processing and analyses of 3-D images of cylindrical soil columns in a semi-automatized way. Thus, the soil column outlines are automatically detected, and the column is moved into the centre of the image canvas. As a next step, unused canvas is cut away as well as image slides depicting the air and the Styrofoam above and below the soil column, respectively. Next, the gray scale of all the five 16-bit images were calibrated to values of 5,000 for air and 20,000 for aluminium layer-bylayer. The value for the column wall was used as the reference for aluminium and the 0.1 percentile of the grayscale value sampled inside the soil column was employed as the reference value for air. Joint histograms were calculated for the five calibrated 3-D images and a joint-threshold grayscale value of 10,171 was determined by the minimum method (Tsai, 1987) and used to obtain binary images depicting the X-ray resolvable pores as described by Hellner et al. (2018).

After the samples had been scanned, saturated hydraulic conductivity was measured for each sample at the same facility (SLU) using the constant head method.

The macro-porosity, critical pore diameter and fractal dimension were determined, after image acquisition, thresholding and image post-processing as described by Koestel et al. (2018). The macro-porosity was defined as the total porosity visible at the applied resolution of $0.04 \mathrm{~mm}$. The critical pore diameter is the smallest diameter of the most extensive pore cluster connecting from top to bottom of the sample. The fractal dimension was the key property for analysing structural development, as the higher it is, the more variable and complex the soil structure is.

\subsection{Data analyses}

Data normality was assessed using the Shapiro-Wilk test $(\mathrm{p}<0.05)$. Data on soil texture, water retention characteristics, macro- and micro-aggregate stability, water balance components and plant properties were analysed for treatment effects with one-way analysis of variance (ANOVA) using the Minitab ${ }^{\circledR}$ Statistical Software (Minitab, 2019). Means were compared using Tukey's mean separation test at $p<0.05$. As the soil water retention curves were measured in two replicates, the comparison of the means was performed for the treatments with and without compost application. The variance was calculated for all the treatments separately for samples of sandy and loamy soils. 


\section{RESULTS}

\subsection{Soil texture and the amount of macro-aggregates}

We found significant differences in the textural composition of the soil samples with different amendments in both soil types (Figure 2). Compared to the small amount of amendments applied, the DG, $\mathrm{C}$ and $\mathrm{VC}$ treatments caused up to a $7 \%$ increase and a $5 \%$ decrease in the silt content of the sandy and loamy soils, respectively.

Probability density functions (PDF) of soil particles are shown in Figure 3. The sand and loamy soil samples presented a main peak at around 125-210 and 15-35 $\mu \mathrm{m}$, respectively. Mixing the soil with different amendments in a small quantity did not cause any shifts in the mean particle size, but slightly modified the PDFs. In case of sand, the slight shift in PDF was visible towards both, smaller $(10-40 \mu \mathrm{m})$ and larger (400-1800 $\mu \mathrm{m})$ particles. For samples with loamy soil, there was an increase in the relative amount of particles in the $200-500 \mu \mathrm{m}$ range.

The textural composition and amount of macro-aggregates $(>250 \mu \mathrm{m})$ of the studied soils with compost or vermicompost applications as compared to MF are given in Figure 4. With the exception of the clay content of the loamy soil, differences in clay, silt, and sand contents between the MF and (vermi)composted treatments were statistically significant, showing slight increase and decrease in the silt content for sandy and loamy soil, respectively. We found opposite tendencies in the sand content in the two soil types. The amount of large aggregates increased by 4 and $1.6 \%$ after applying compost or vermicompost to the sandy and loamy soils, respectively.

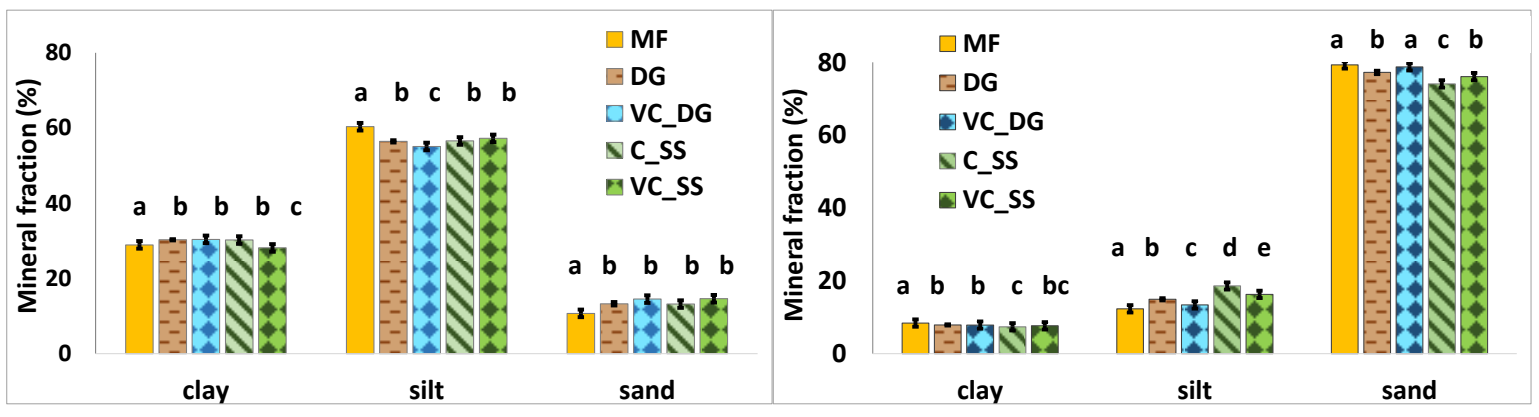

Fig. 2. Textural composition of sandy (left) and the loamy (right) soil with different amendments. MF: mineral fertilizer; DG: digestate; VC_DG: vermicomposted DG; C_SS - composted sewage sludge; VS_SS: vermicomposted sewage sludge. Different lowercase letters indicate significant differences between treatments (Tukey's test, $\mathrm{p}<0.05, \mathrm{n}=6$ ).
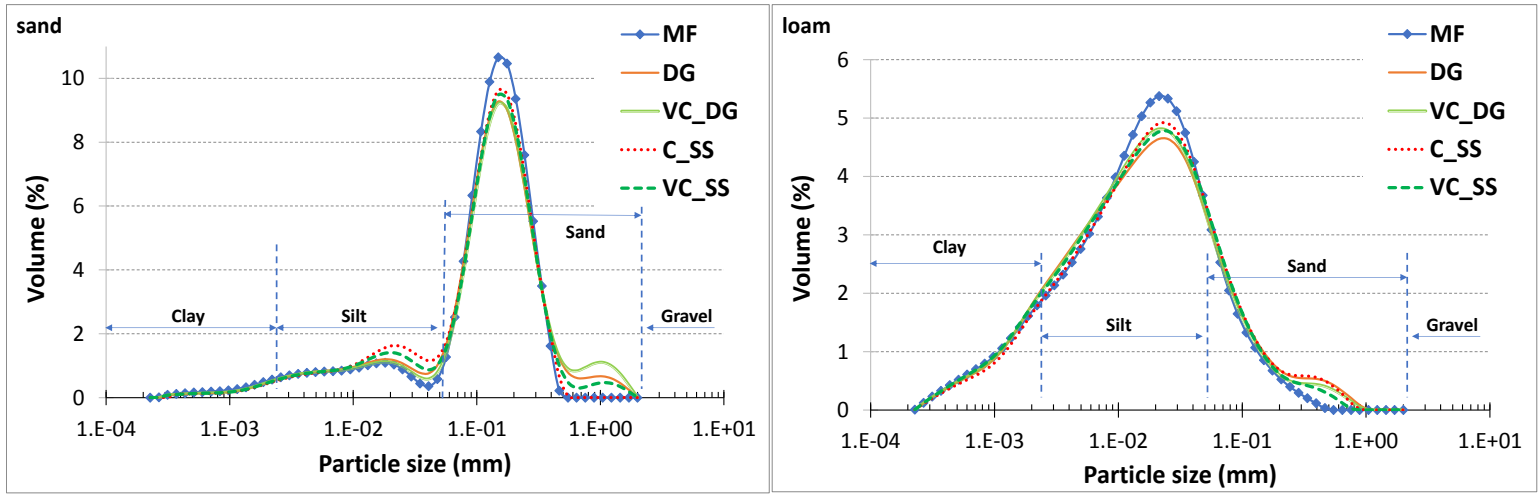

Fig. 3. Probability density functions of soil particles for derived for sandy (left) and loamy (right) soil with different amendments. MF: mineral fertilizer; DG: digestate; VC_DG: vermicomposted DG; C_SS - composted sewage sludge; VS_SS: vermicomposted sewage sludge.
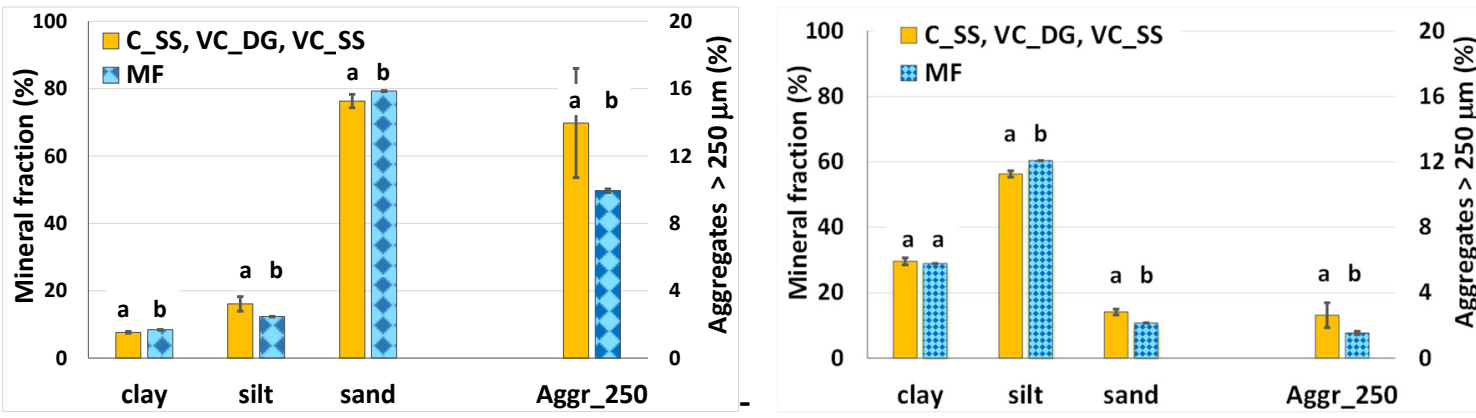

Fig. 4. Textural composition and amount of large aggregates in the sandy (left) and loamy (right) soil with compost (C SS; VC DG; VC_SS) as compared to the control treatment (MF). Different lowercase letters indicate significant differences between treatments (Tukey's test, $\mathrm{p}<0.05, \mathrm{n}=3(\mathrm{MF})$ or $9(\mathrm{C}, \mathrm{VC}))$. 


\subsection{Soil aggregate stability}

We observed a substantial increase in the micro-aggregate stability in the sandy soil when amended with any of the treatments (Figure 5). There were markable differences between the $\mathrm{MF}$ and the all the other treatments, ranging from 5\% (VC_DG) to about $10 \%$ (C_SS and VC_SS). The differences appeared to be statistically significant between the MF and the C_SS and VC_SS treatments. We observed no statistically significant differences either between the digestate and vermicomposted digestate (DG and VC_DG) or between the composted and vermicomposted sewage sludge (C_SS and VC SS).

Smaller changes in MiAS were found in the loamy soil, where we observed reduced aggregate stability compared to the control (MF) by at least $2.9 \%$ (C_SS) and up to $4.1 \%$ (VC_DG). The MiAS was significantly lower between MF and the other treatments and no statistically significant differences were found between the various treatments with organic amendments.

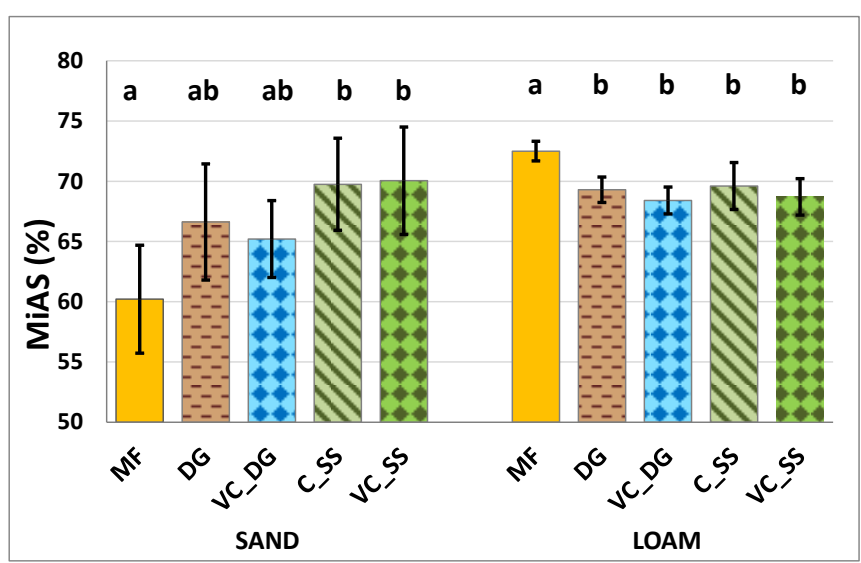

Fig. 5. Micro-aggregate stability of the sandy and loamy soils with various amendments. MF: mineral fertilizer; DG: digestate; VC_DG: vermicomposted DG; C_SS - composted sewage sludge; VS_SS: vermicomposted sewage sludge. Different lowercase letters indicate significant differences between treatments (Tukey's test, $\mathrm{p}<0.05, \mathrm{n}=6$ ).

Concerning the macro-aggregate stability, the overall picture differed from that found during the micro-aggregate stability analyses. In the sandy soil, we found a significant increase in MaAS in all the treatments compared to MF (Figure 6). The greatest, up to $9 \%$ increase was found for the DG treatments,

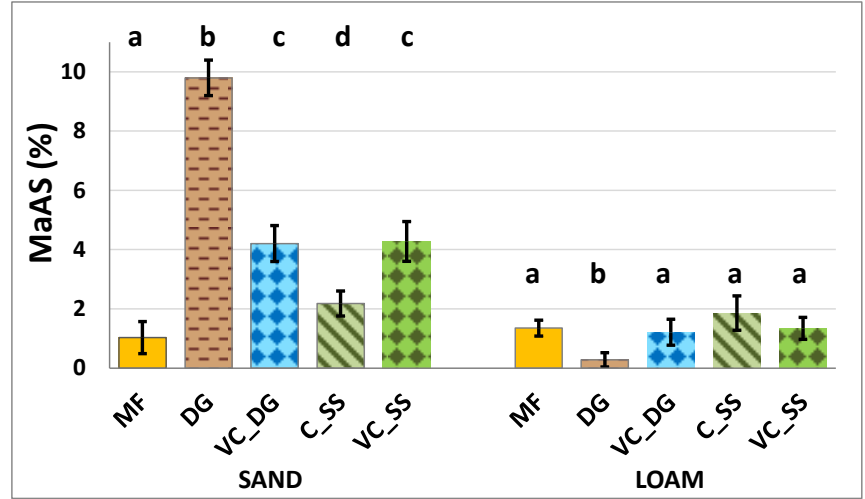

Fig. 6. Macro-aggregate stability of the sandy and loamy soils with various amendments. MF: mineral fertilizer; DG: digestate; VC_DG: vermicomposted DG; C_SS - composted sewage sludge; VS_SS: vermicomposted sewage sludge. Different lowercase letters indicate significant differences between treatments (Tukey's test, $\mathrm{p}<0.05, \mathrm{n}=6$ ).

followed by an up to $4 \%$ increase in the vermicomposted treatments (VC_DG and VC_SS). Concerning the loamy (Chernozem) soil, there were no statistically significant differences between the treatments, with the DG treatment being the only exception. The MaAS in the DG treatment was the lowest $(0.3 \%)$, and it varied from 1.21 to $1.86 \%$ in the other treatments.

\subsection{Bulk density and soil water retention curves}

The water retention curves measured in the different treatments of the sandy and loamy soils are given in Figures 7 and 8 . The saturated water content varied from 0.31 to $0.40 \mathrm{~m}^{3} \mathrm{~m}^{-3}$ in the treatments with sandy, and between 0.39 and $0.45 \mathrm{~m}^{3} \mathrm{~m}^{-3}$ in the loamy soil and was the highest in the sewage sludge (SS)-based vermicompost and compost, respectively. More marked differences were observed in the field capacity, which varied from 0.12 to $0.19 \mathrm{~m}^{3} \mathrm{~m}^{-3}$ in the samples with sandy, and from 0.31 to $0.34 \mathrm{~m}^{3} \mathrm{~m}^{-3}$ in the samples with loamy soil.

Generally, compost addition increased the water holding capacity and reduced the bulk density of both soil types. For the sandy soil, we found that composting and vermicomposting caused significant differences between the characteristic points of the water retention curve in the whole examined water potential range, except for $-10 \mathrm{hPa}$ (Figure 9). Up to $0.04 \mathrm{~m}^{3} \mathrm{~m}^{-3}$ differences between the water contents corresponding to different water potentials were found for the loamy soil, which were not statistically significant, however (Figure 10).

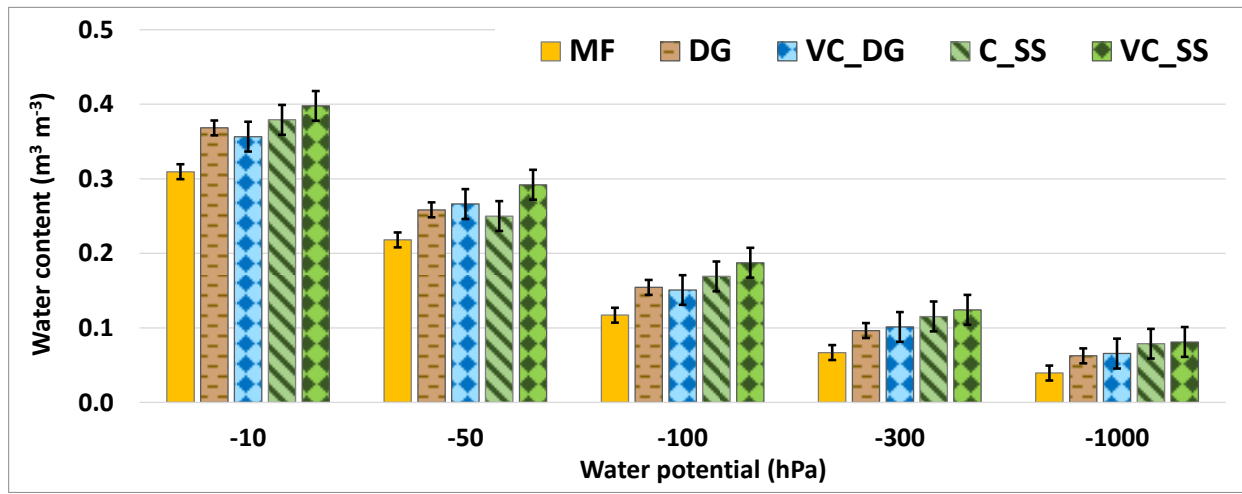

Fig. 7. Water retention capacity of the sandy soil in different treatments. MF: mineral fertilizer; DG: food waste digestate; VC_DG: vermicomposted DG; C_SS: composted sewage sludge; VS_SS: vermicomposted sewage sludge. 


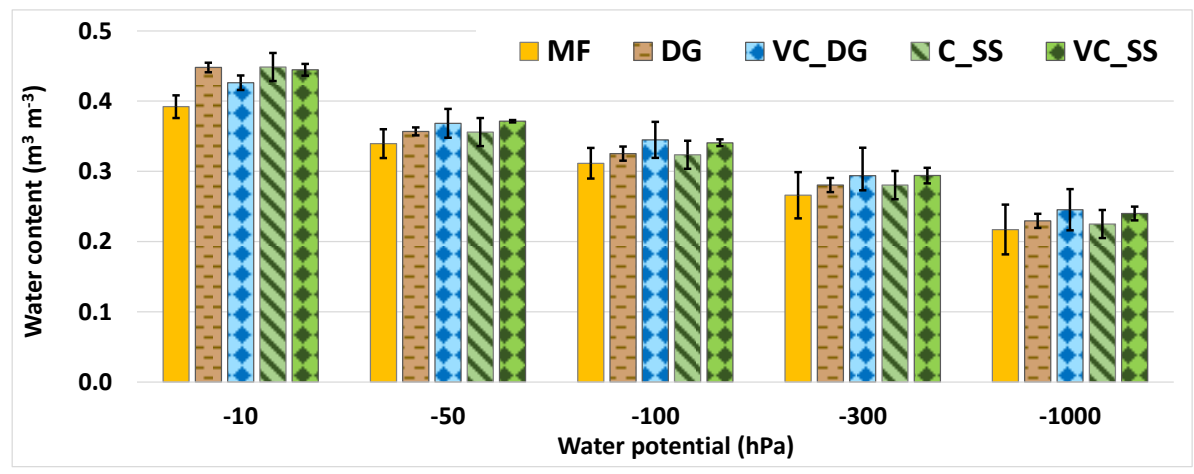

Fig. 8. Water retention capacity of the loamy soil in different treatments. MF: mineral fertilizer; DG: digestate; VC_DG: vermicomposted DG; C_SS - composted sewage sludge; VS_SS: vermicomposted sewage sludge.

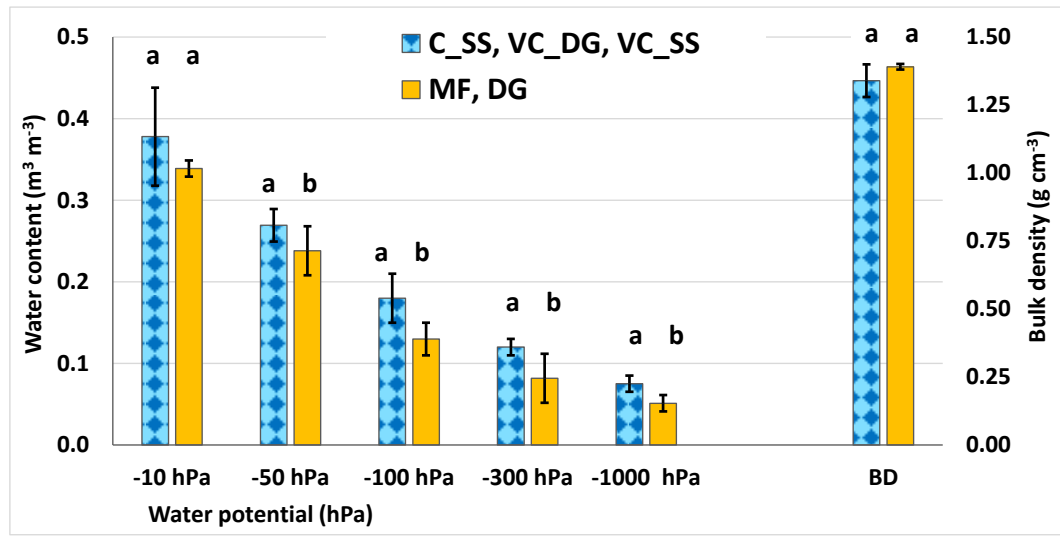

Fig. 9. Water retention capacity and bulk density (mean values and standard deviations) of the sandy soil measured in treatments with (C_SS, VC DG, VC SS) and without (MF, DG) (vermi)compost amendments. Different lowercase letters indicate significant differences between treatments (Tukey's test, $\mathrm{p}<0.05, \mathrm{n}=4$ (MF, DG) $6(\mathrm{C}, \mathrm{VC})$ ).

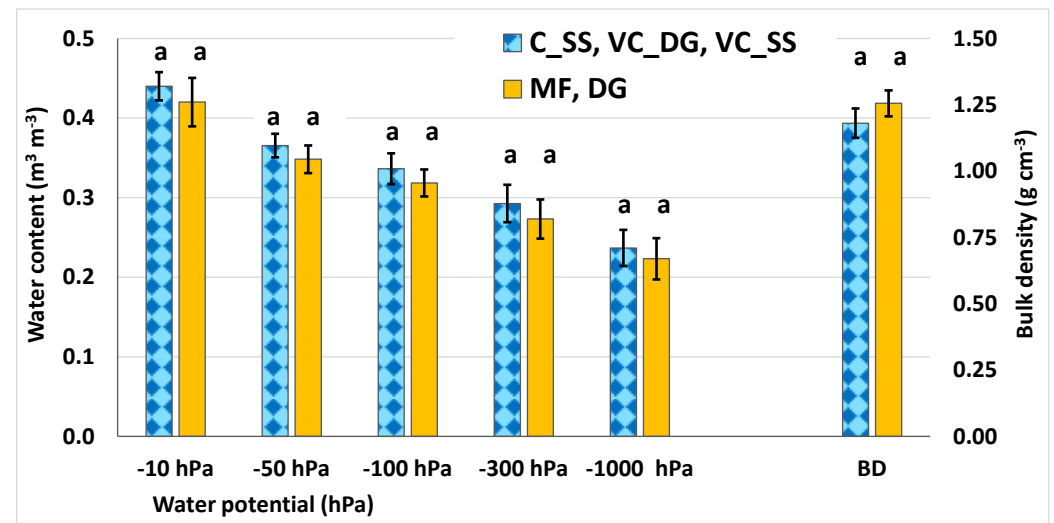

Fig. 10. Water retention capacity and bulk density (mean values and standard deviations) of the loamy soil measured in treatments with (C_SS, VC_DG, VC_SS) and without (MF, DG) (vermi)compost amendments. Different lowercase letters indicate significant differences between treatments (Tukey's test, $\mathrm{p}<0.05, \mathrm{n}=4$ (MF, DG) $6(\mathrm{C}, \mathrm{VC})$ ).

\subsection{Soil water regime}

The soil water balance components, evaluated as an average of the three replicates for the whole experimental period, except soil evaporation, are given in Figure 11. Evaporation from the soil surface was measured in one replicate, therefore those data are presented without statistical evaluation. Transpiration (TR) shows the amount of water consumed by the plant during the experimental period, and the ratio between TR and the amount of water used for irrigation (I) is a measure of the irrigation efficiency (IE).

In the sandy soil, all the treatments had a beneficial effect on reducing the outflow. We registered $238 \mathrm{ml}$ loss of water from the control pots (MF) on average, whereas only $45 \mathrm{ml}$ from the DG treatment, and basically no outflow was registered from the other treatments. Differences between MF, DG and the treatments with composting were statistically significant. Reduced evaporation from the soil surface was the other favourable outcome of soil composting. A total $1235 \mathrm{ml}$ water evaporated from the surface of the sandy soil with mineral fertilizer (MF), the evaporation from the other treatments varied from 910 to $945 \mathrm{ml}$. Transpiration varied from 754 (DG) to 906 (VC_DG) $\mathrm{ml}$ between the treatments compared to the $667 \mathrm{~mL}$ calculated for the control (MF). Differences in TR were statistically significant in all cases. 


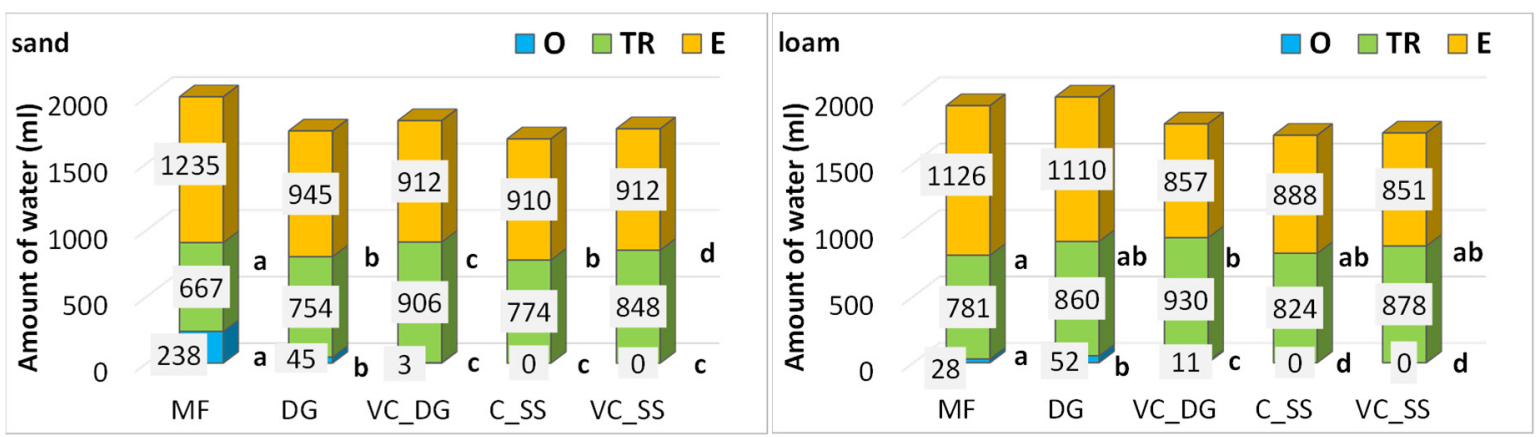

Fig. 11. Cumulative soil water balance components (average of 3 replicates) of the sandy (left) and loamy (right) soil during the total period of the experiment (O - outflow; TR - transpiration; E - evaporation). MF: mineral fertilizer; DG: digestate; VC DG: vermicomposted DG; C_SS - composted sewage sludge; VS_SS: vermicomposted sewage sludge. Different lowercase letters indicate significant differences between treatments (Tukey's test, $\mathrm{p}<0.05, \mathrm{n}=3$ ).

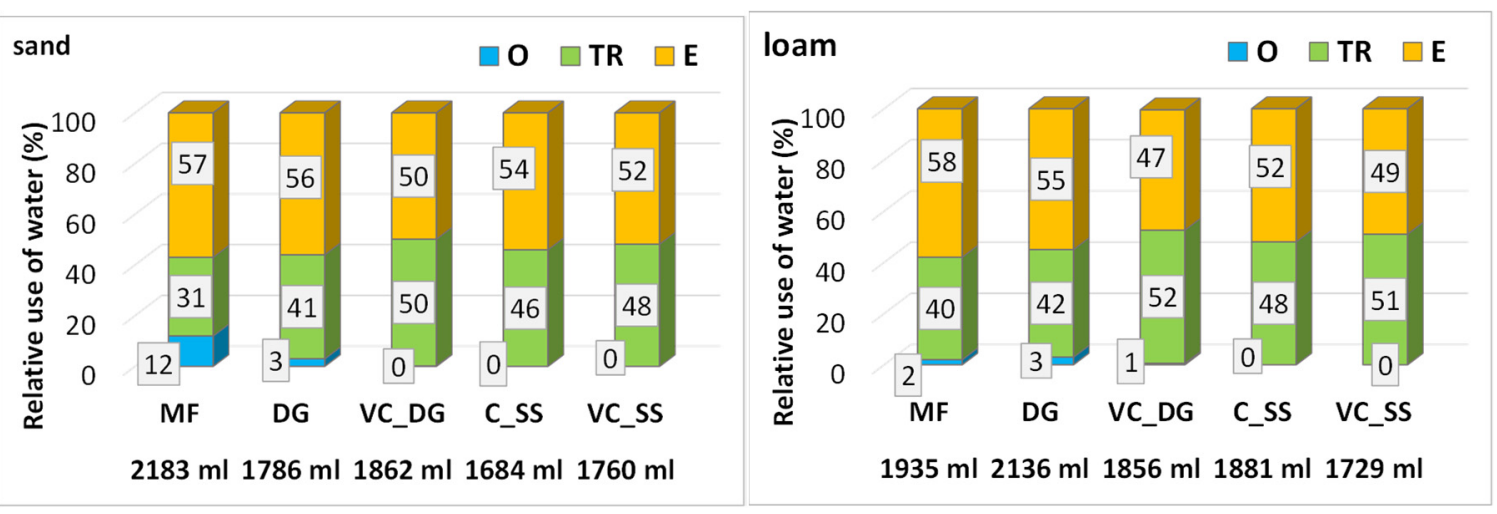

Fig. 12. Relative use of water in the different treatments (average of 3 replicates). The total amount of water used for irrigation is indicated in millilitres. (O - outflow; TR - transpiration; E - evaporation). MF: mineral fertilizer; DG: digestate; VC_DG: vermicomposted DG; C_SS - composted sewage sludge; VS_SS: vermicomposted sewage sludge.

Compared to the sandy soil, lower evaporation and higher transpiration values and minimal outflow were registered from the treatments with loamy soil (Figure 11, right). The evaporation was the highest in the MF $(1126 \mathrm{~mL})$ and $\mathrm{DG}(1110 \mathrm{~mL})$ treatments, whilst much lower and rather similar values - varying between 851 and 888 - were recorded in the VC_SS, VC_DG and C_SS treatments. Regarding transpiration, the lowest and highest values of 781 and $930 \mathrm{~mL}$ were detected in the MF and VC_DG treatments, respectively, and this difference was statistically significant. TR values, varying from 824 to $878 \mathrm{~mL}$ in the DG, C SS and VC SS treatments did not differ significantly from either the MF or the VC_DG treatments.

We evaluated the apportionment of the water used for irrigation in the different treatments during the whole period of the experiment (Figure 12). According to the irrigation schedule, the pots received different amounts of water depending on the water loss between the irrigation events, as pots were watered individually to maximum water holding capacity. In that sense, the MF treatments performed poorest for both soil types, but especially for the sandy soil, where only $31 \%$ of the irrigation water was used by the plants (cf. transpiration, TR in the figures). The rest of the water was lost to gravity $(12 \%)$ or evaporated from the soil surface $(57 \%)$ (Figure 12, left). We used $1935 \mathrm{~mL}$ of water for irrigation in the same MF treatment of the loamy soil (Figure 12, right) and $40 \%, 2 \%$ and $58 \%$ of that was used for transpiration, outflow, and evaporation, respectively.

The IE (being equal to TR in Figure 12) was the best in the VC_DG and VC_SS treatments (50 and 48\%, respectively) for the sandy soil, while around $41-46 \%$ of the irrigation water was transpired by the plants in the other treatments with soil amendments. In the loamy soil, the highest ratio of irrigation water was similarly used by the plants in the VC_DG and VC SS treatments, i.e. $52 \%$ and $51 \%$ respectively (Figure 12 , right), followed by C_SS (48\%). In both soil types, the MF was the most water demanding soil amendment with the lowest IE, whilst the IE was the highest in the pots treated with vermicompost (VC_DG and VC_SS).

Plant water use efficiency (WUE, Figure 13) was significantly lower for treatments with high irrigation demand (MF and DG), and somewhat higher in the loamy soil than in the sand. For both soil types, the production of $1 \mathrm{~kg}$ dry shoot biomass required the greatest amount of water in the MF and DG treatments, respectively. The lowest and the highest WUE was detected in pots receiving DG and VC_DG, respectively, and vermicomposting improved WUE relative to that of food digestate by 0.9 and $1.1 \mathrm{~kg} \mathrm{~m}^{-3}$ in the sand and loam, correspondingly. Concerning the sewage sludge-based compost materials, the WUE appeared to be slightly better in the vermicomposted treatments (VC_SS) than in the composted treatments (C_SS), but these differences were not statistically significant.

\subsection{Results of X-CT imaging}

In Figures 14 and 15 we present images of samples showing contrasting pore space structure. Figure 14 refers to horizontal, and Figure 15 to the vertical cross-section of the sandy soil columns taken from the MF and VC_SS treatments, respectively. 


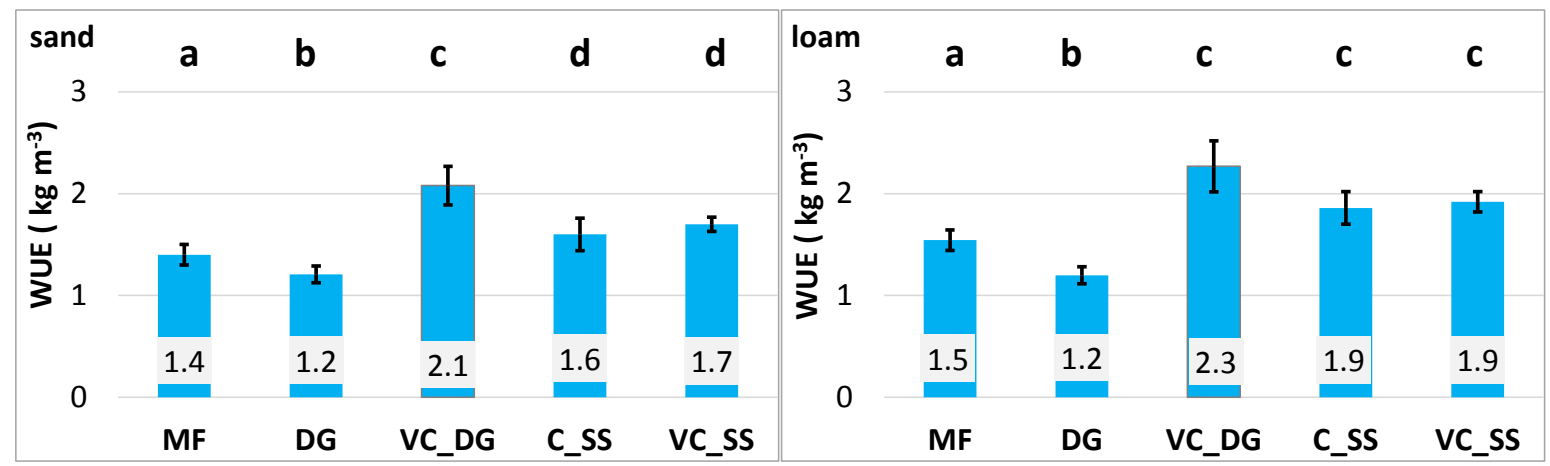

Fig. 13. Plant water use efficiency (WUE) in the different treatments. MF: mineral fertilizer; DG: digestate; VC_DG: vermicomposted DG; C_SS - composted sewage sludge; VS_SS: vermicomposted sewage sludge. Different lowercase letters indicate significant differences between treatments (Tukey's test, $\mathrm{p}<0.05, \mathrm{n}=3$ ).

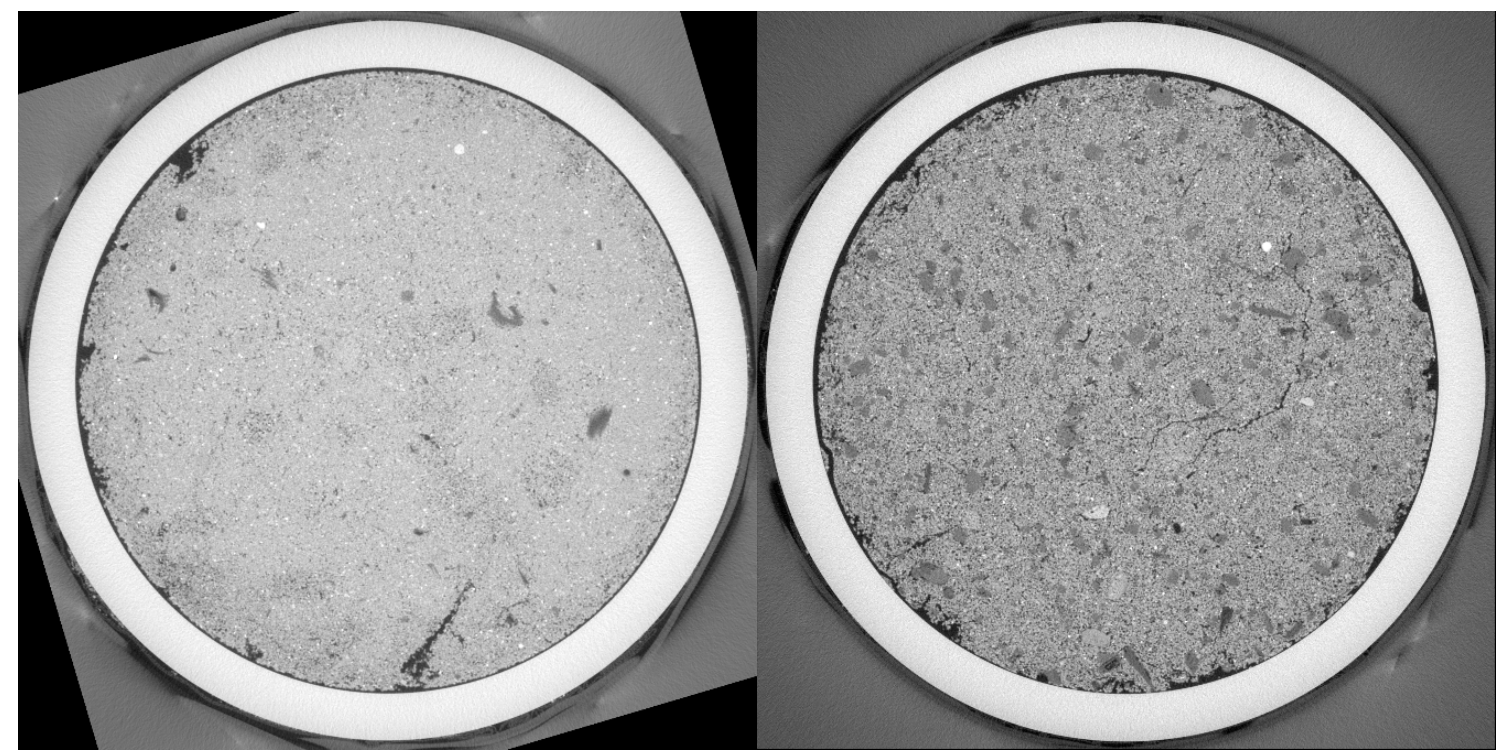

Fig. 14. X-rays images of horizontal cross sections through the middle of soil columns MF (left) and VC_SS (right).
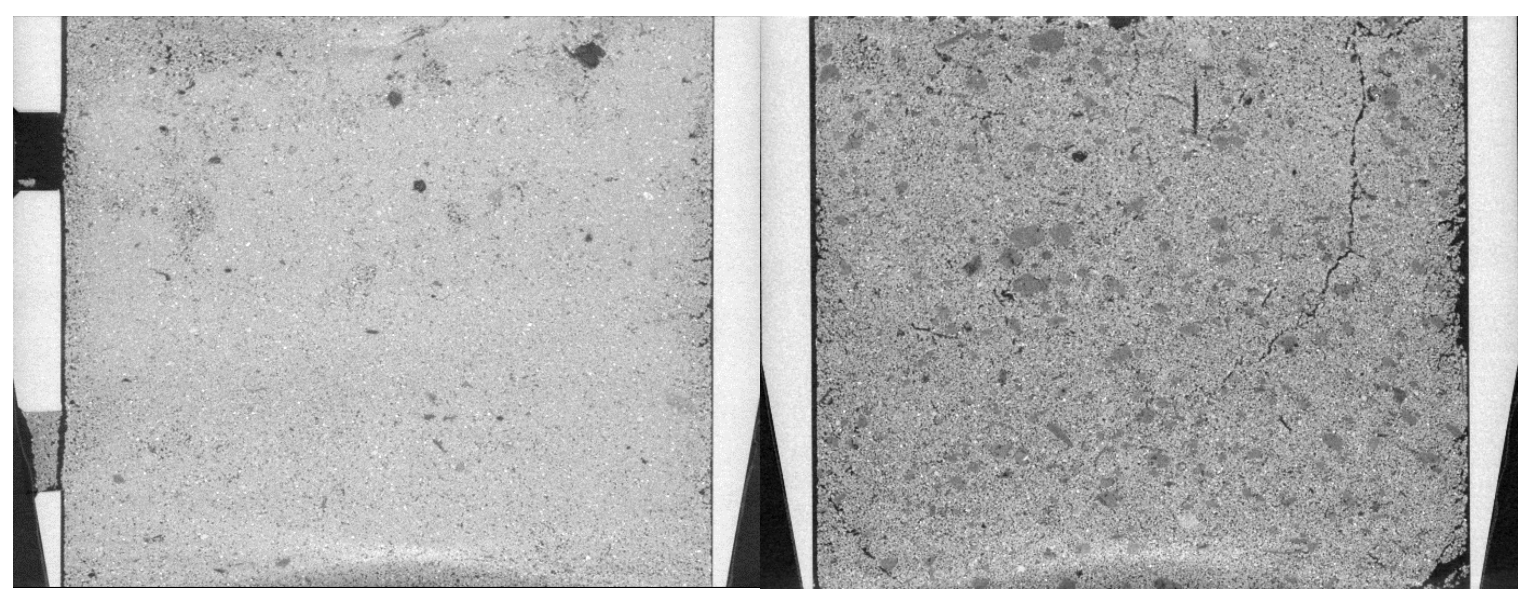

Fig. 15. X-ray images of the vertical cross sections through the middle of soil columns MF (left) and VC_SS (right).

Compared to the control (MF) treatment, the VC_SS treatment showed visible increase in heterogeneity of soil body and increase in the number and length of visually detective pores. Images from the control treatment gave typical picture for poorly structured, rather homogenous sandy soils with small number of pores. The images of the VC_SS, C_SS and VC_DG treatments (the latter two not presented) showed more diverse and less compacted pattern, with several continuous pores in both, horizontal and vertical direction. Soil structural characteristics measured or derived from X-ray images (Table 2) were in line with these observations.

The measured saturated hydraulic conductivity $\left(K_{s}\right)$, imaged macro-porosity, critical pore diameter and fractal dimension are summarised in Table 2. 
Table 2. Saturated hydraulic conductivity $\left(K_{s}\right)$, macro-porosity, critical pore diameter and fractal dimension determined for the different treatments in the sandy soil.

\begin{tabular}{lcccc}
\hline Treatment & $\begin{array}{c}\mathbf{K}_{\mathbf{s}} \\
\left(\mathbf{c m ~ h} \mathbf{-}^{-\mathbf{1}}\right)\end{array}$ & $\begin{array}{c}\text { Macro porosity } \\
\mathbf{( \% )}\end{array}$ & $\begin{array}{c}\text { Critical pore } \\
\text { diameter } \\
(\mathbf{m m})\end{array}$ & $\begin{array}{c}\text { Fractal } \\
\text { dimension }\end{array}$ \\
\hline MF & 7.59 & 1.10 & $\mathrm{NA}$ & 2.22 \\
DG & 9.78 & 3.13 & 0.016 & 2.38 \\
VC_DG & 9.78 & 4.98 & $\mathrm{NA}$ & 2.82 \\
C_SS & 8.75 & 3.87 & $\mathrm{NA}$ & 2.78 \\
VC_SS & 8.84 & 4.40 & 0.016 & 2.69 \\
\hline
\end{tabular}

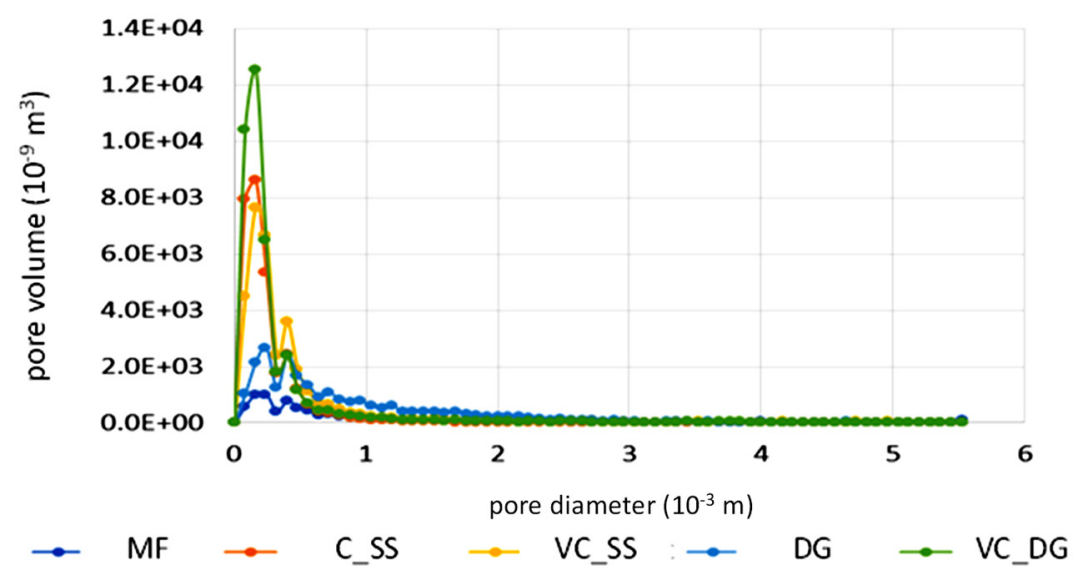

Fig. 16. Pore-size distribution of the soil samples from different treatments determined by X-CT imaging.

$K_{s}$ did not correlate with any of the parameters shown in able 2 , and it did not vary a lot between the treatments. The macro-porosity was three-four-fold higher in treatments with amendments compared to the control (MF). Imaged pore clusters reaching from top to bottom of the sample were detected in two treatments only (DG and VC_SS), whilst no such pore cluster was detectable in the other three treatments at the given resolution. All treatments with organic amendments resulted in higher fractal dimension values than the FM treatment.

The pore-size distribution (Figure 16) demonstrated that the pore volumes corresponding to rather small pores (with pore diameter less than $1 \mathrm{~mm}$ ) are more significant in the composted (C_SS) and vermicomposted (VC_DG and VC_SS) treatments.

The fractal dimension (FD) of the pore size was the highest in the VC_DG (2.82) treatment, followed by the C_SS (2.78) and VC_SS (2.69). Relatively low FD values of $2.2 \overline{2}$ and 2.38 were found in the MF and DG treatments, respectively. The higher the FD, the more variable and complex the soil structure is, and the better the water holding capacity and water regime of the soil become.

\section{DISCUSSION}

\subsection{Soil texture and the amount of large aggregates}

There is very limited information in the scientific literature about the effects of organic amendments on soil texture (e.g., Duong et al., 2012). Bucka et al. (2019) did not find significant differences in soil texture after 30 days of organic matter application. Our results, however, indicate that depending on the type of the amendments, minor changes in soil textural composition can occur after organic amendment application (Figures 2 and 3), but they are only detectable with very precise measurements. The particle size distribution was found to be somewhat less uniform after amendments application (Figure 3), showing lower peaks around the dominant particle size and increased volume in the silt and coarse send fraction (sandy soil) or in the coarse sand fraction (loamy soil). It is possible that the sewage sludge and digestate were precipitated with dispersing agents causing a slight shift between the different textural classes. In addition, enrichment of certain size-fractions by solids originating from the amendments may have occurred - especially in the coarse sand size range (Figure 3), and there are also documented imperfections to the internal re-sampling process of the LDM method itself (Polakowski et al., 2015; Sochan, 2012).

The increase in the amount of large aggregates (by 4\%) due to compost application was larger in the sandy soil and not that well expressed, but still significant in the loamy soil, reaching $1.6 \%$ (Figure 4). Bucka et al. (2019) studied the amount and texture of the aggregate size fractions of an artificial soil microcosmos, using wet-sieving and sedigraph analysis after 30 days of particulate and dissolved organic matter application. They found that the largest proportion of the organic amendments were bond in the aggregates and that the presence of macroaggregates $(>200 \mu \mathrm{m})$ was predominant. Other studies also report accelerated macroaggregation after applying organic amendments to soil (Yu et al., 2015). Wortmann and Shapiro (2008) reported that compost application resulted in a significant increase in water-stable large macro-aggregates within 15 days after application, most probably due to the consolidation of smaller aggregates. Our findings were similar, indicating, that composting, and vermicomposting promote the formation of macro-aggregates within a short period after their application. 


\subsection{Aggregate stability}

We found the most profound changes in aggregate stability due to amendment application in the sandy soil in the macroaggregate range, where we observed an increase in MaAS in almost all the treatments (Figure 6) compared to the control (MF). The high MaAS values detected in the digestate may be related to its texture. This material contains big clumps that are difficult to incorporate into the soil properly; we assume that the poorly incorporated clumps could interfere with the measurements. Our data indicate that within the study period, vermicomposting contributed to an increase in macro-aggregate stability in the sandy soil compared to simple composting, as the MaAS of the VC_SS treatments was nearly double $(4.2 \%)$ of that of the C_SS $(2.2 \%)$.

Numerous studies have reported favourable effects of compost application on soil aggregate stability (Horel et al., 2019; Leroy et al., 2008), but not many of them discuss macro- and micro-aggregate stability separately. Abiven et al. (2009) carried out a detailed literature analysis of more, than 80 studies on the effects of organic inputs on soil aggregate stability. To make all the data comparable, they defined the maximum relative effect (RE) of soil organic amendments on aggregate stability as the ratio between the aggregate stability of the soil with the organic amendment (AS assumed higher) and without the amendment. Out of the more, than 100 organic amendments there were 16 composts and one vermicompost, most of which had moderate (RE between 1 and 1.3) or strong (RE above 1.3) relative effect. In our study, the RE for the macro-aggregates in the sandy soil was approximately 2 and 4 for the compost (C_SS) and vermicomposts (VC_DG and VC_SS), respectively. In the loamy soil, it varied from 1.3 for the compost (C_SS) to 0.9 and 1 for the vermicomposts, respectively. Composting and vermicomposting did not affect the MaAS of the loamy soil. We assert that these soils have a well-developed and stable structure that does not respond to the addition of small amounts of organic amendments, and likely does not need structural stabilization either.

Our results indicate, that the RE of compost application, with respect to MaAS depends on the soil texture, and stronger effect can be expected on soils with poor structure and whether vermicompost has been applied instead of compost. Similar to our findings, Bronick and Lal (2005) argued that soil texture has a major influence on aggregation of soil particles. They proposed that a greater influence of soil organic carbon on soil structure formation can be expected in coarse-textured soils, while with increasing clay content the type of the clay, rather than its abundance is more important in determining aggregate formation.

We observed contradictory effects of organic amendments on the micro-aggregate stability of the sandy and loamy soils. The RE was above 1 for all the organic amendments in the sandy soil but remained below 1 in the loamy soil. A slight structural stabilization was seen in the sandy soil with $\mathrm{RE}$ values of 1.1 in the DG and VC_DG, and 1.2 in the C_SS and VC_SS treatments. The opposite tendency was observed in the loamy soil in which all the treatments reduced micro-aggregate stability compared to the control (i.e., RE equalled 0.94-0.96). Still, even after this reduction, the micro-aggregate stability was comparable or higher in the loamy soil than in the treated sandy soil samples. Since the loamy soil involved in this study is well-structured and has a favourable water regime, the slight reduction in MiAS was not crucial. Therefore, it has to be carefully assessed if the application of organic amendments is worth the investment if a soil's relevant structural and functional properties are favourable.
Studies focusing on the relationship between organic amendments and aggregate stability of growing media report that aggregate stability predominantly increases for all soil types (Abiven et al., 2009), although the opposite has also been reported by some (Bronick and Lal, 2005; Haynes and Naidu, 1998). Haiti et al. (2008) asserts that aggregate stability is positively correlated with soil organic carbon content. Therefore, it is expected that the addition of organic fertilizers or materials rich in organic carbon such as manure or sludge or composts will improve the aggregation status of the soil. However, Bronick and Lal (2005) proposed that certain cations $\left(\mathrm{Na}^{+}\right.$and $\left.\mathrm{K}^{+}\right)$ can enhance dispersion of soil aggregates. Haiti et al. (2008) further explains that, particularly in humid temperate regions, the introduction of surplus monovalent cations may decrease aggregate stability by replacing bivalent cations $\left(\mathrm{Ca}^{2+}\right.$ and $\mathrm{Mg}^{2+}$ ) that may eventually leach from the soil. Haynes and Naidu (1998) support the finding of soil structural breakdown after organic fertilizer application by referring to the high content of monovalent cations $\left(\mathrm{Na}^{+}\right.$and $\left.\mathrm{K}^{+}\right)$in the waste materials and the accumulation of high concentration of $\mathrm{NH}^{+}$through mineralization of $\mathrm{N}$ in organic wastes. Therefore, the observed response in aggregate stability is likely the product of a delicate balance between such opposite effects, and the positive effect is not guaranteed under all circumstances.

\subsection{Bulk density and water retention characteristics}

The soil water retention curve is an indicator of the soil's pore-size distribution. By theory, soil water retention in the low water potential range (high $\mathrm{pF}$ values) is influenced mainly by textural properties and microporosity. In contrast, in the high water potential range (in the $0-100 \mathrm{hPa}$ water potential range), it is driven by both soil textural and structural properties.

In our experiment, the effect of soil amendments on the soil water retention characteristic was more pronounced for the sandy than the loamy soil. Despite the short period of the experiment, the addition of a small amount of compost material could increase the saturated water content and field capacity of the sandy soil by approx. 4\% and 6\%, respectively (Figure 9), most probably because this soil type has poor structure and any improvement to its structural properties can in turn have a pronounced effect on its soil water retention characteristic. However, we also found statistically significant differences between the water contents measured in the lower water potential range (i.e. at water potentials of -300 and $-1000 \mathrm{hPa}$ in this study), indicating that the textural and MiAS differences found between the different treatments have a more generally visible effect on the water retention curves as well. In the loamy soil, we did not find statistically significant differences in the soil water retention characteristics between treatments. However, we note that the (vermi)compost application did result in a less expressed but consistent increase in water retention capacity. In terms of bulk density, we recorded a limited but consistent $4 \%$ and $6 \%$ decrease of bulk density in the sandy and loamy soils, respectively.

Numerous studies have reported reduced soil bulk density and increased soil water retention capacity after compost incorporation into soil. Kranz et al. (2020) compared twenty-five peer-reviewed studies that evaluated the changes in soil physical and hydraulic properties after compost incorporation into urban soils of various textures. They reported a $6-55 \%$ decrease in bulk density in different soil types, at different compost application rates, at different incorporation depths and with different compost feedstocks. The reported change was usually more expressed in soils with sandy texture, and it remained 
below $16 \%$ for clay and loamy clay soils. In their review Kranz et al. (2020) also reported the effect of compost material on soil water retention, based on six studies. All the referred studies reported an increase in soil water retention and either an increase or no significant change in the plant-available water content. Our results appear to be consistent with this, since we have found that adding composted or vermicomposted soil amendments increased soil water retention in the entire examined water potential range.

\subsection{Soil water regime}

All the organic amendments applied had a favourable effect on the soil water regime, compared to the MF treatment, since they enhanced soil water retention and reduced evaporation from the soil surface. Structural improvement was also visible on how cracks formed, since fewer and smaller (or no) cracks were visually observed on the soil surface with organic amendments compared to the control treatment (data not shown). Cracks had an unfavourable effect on the water regime as they facilitated preferential flow that allowed some of the irrigation water to bypass the root zone, thereby increasing outflow, reducing the amount of water available to the plant, and increasing irrigation demand.

Significantly higher WUE was found in the composted and vermicomposted treatments for both soil types. Therefore, we concluded that adding composted amendments, in general, resulted in lower irrigation demand and higher shoot biomass per unit of irrigation water. Similar results were found by Hashem et al. (2014) when comparing the irrigation demand and water use efficiency of soil treated with organic mulch, agricultural residues, compost and vermicompost. Hashem et al. (2014) have also concluded that vermicomposting was the most efficient treatment in reducing the irrigation demand and increasing the WUE.

The examined soil water balance components and the plant water use efficiency (WUE) calculated for the two different soil types and all the treatments underlined our hypothesis that organic soil amendments can improve soil structure and soil water retention and, in turn, may facilitate an improved soil water regime.

\subsection{X-CT imaging}

We evaluated the pore system and the soil structural status of all the treatments in the sandy soil using X-CT imaging. The undisturbed topsoil of the composted and vermicomposted treatments (see Figure 14 for VC_SS and the control) showed higher soil porosity and larger variability in the size of visualised pores. Compared to the MF treatment, visible increase in the number of discontinuous and continuous pores could be detected in the treatments with soil amendments in both, horizontal and vertical (Figure 15) directions. As pore morphology affects the movement of air and water through the soil as well as water retention (Yang et al., 2018), the increased number of discontinuous pores could contribute to improved water retention in the soil, while improved pore continuity may facilitate water transport.

Soil properties, derived from the images were in line with our visual observations. We found notable differences between the structural properties of soils under the VC_DG, C_SS and VC_SS treatments compared to those of the MF and DG. Macroporosity was higher in the treatments with amendments compared to the control (MF). The pore volume of the visible pores was about four times higher in the C_SS and VC_SS, and six times higher in the VC_DG treatments than in the untreated soil (Table 2 and Figure 16). The fractal dimension (FD) of the pore size was higher in the VC_DG, C_SS and VC_SS treatments (varying from 2.69 to 2.82 ) compared to the $\overline{M F}$ and $\mathrm{DG}$ (FD of 2.22 and 2.38, respectively) treatments. Pore size fractal dimension is an integrated indicator of the complexity of the soil structure, higher values referring to more heterogenous and complex pore system. Healthy soil consists of a combination of well-aggregated soil matrix and a well-developed soil pores system. Results from X-ray CT in our study indicate that composting and vermicomposting induced pore space reallocation with a shift from small pores to larger pores thus, promoted soil structural development within a short time.

The application of X-CT imaging is no longer so novel in soil science and is mostly used to visualise and analyse the structure of pores and aggregates. Yet, we could not find any studies focusing specifically on quantifying the effects of adding compost on the soil's pore system using this technology. Yang et al. (2013 and 2018) used X-CT scanning to evaluate the individual and combined effects of various non-compostbased soil organic amendments on soil pore system and soil structure, five months after their application. They found, that compared to the control, all the treatments led to an increased number of macropores and micropores, causing a significant improvement in soil structure and porosity. Singh et al. (2021) also found that long-term manure application significantly enhanced CT-imaged porosity and saturated hydraulic conductivity compared to mineral fertilization and control treatments. From the findings in the literature and our own results we conclude that organic amendments can play an important role in the improvement of the physical structure of poorly structured soils, that may, in turn improve their hydraulic functioning.

We acknowledge that our results are reported based on a relatively short experiment. However, there appears to be independent evidence that aggregate formation may take place in as short a time as 30 days in a loamy textured soil in response to organic matter input (Bucka et al. 2019). The same study also reports that the type/quality of organic matter input may strongly affect the degree of structural development and aggregate formation (Bucka et al. 2019). Our results, together with those of Bucka et al. (2019) appear to confirm that soil amendmentinduced differences in soil structure and water regime can be notable within a few weeks. We assume, however, that the short duration of our experiment may have limited the expression of positive effects on the examined structural and functional soil properties, and in the longer term the compost application may have a more significant beneficial effect on those properties, especially when the soil to be amended already presents somewhat favourable properties. This, however, remains to be experimentally confirmed. While soil structural development can be induced by adding organic soil amendments, it is expected to take a longer time till the formation of soil aggregates - the binding of soil particles by soil organic matter into secondary units - reaches its equilibrium with both the prevailing climatic conditions and the land use.

\section{CONCLUSIONS}

The application of organic amendments to two different soil types (sandy and loamy soils) improved soil water holding capacity, increased the amount of macro-aggregates and reduced soil bulk density even at a small application rate and within a relatively short period of 30 days. This in turn had a favourable effect on irrigation efficiency and reduced the irrigation demand. In both soil types, the control treatment (MF) 
proved to have the lowest irrigation use efficiency, while plants grown in the vermicompost (VC_DG and VC_SS) treatments used irrigation water most efficiently.

The addition of organic amendments also helped increase the micro- and macro-aggregate stability of the sandy soil even within this short study period and those changes have proved significant for most organic treatments. However, we recommend a follow-up study complete with relevant chemical analyses that helps isolating the reason for the observed slight but significant micro-aggregate destabilization in the loamy soil after applying organic amendments.

When testing how potentially improved soil structural and water retention properties translate to improved soil conditions for plant growth, composting and vermicomposting appeared to be the two best treatments in reducing the outflow and evaporation losses and increasing the water use efficiency of the plant. $\mathrm{X}$-ray computed tomography imaging of the sandy samples have confirmed that adding composted and vermicomposted amendments resulted in a more complex and diverse porous system and increase in macroporosity compared to the other treatments. The obtained fractal dimensions and the visualised pore-structure of the sandy soil supported our hypothesis that compost and vermicompost can contribute to structure formation within a relatively short time after their application.

Acknowledgement. This work was funded by the Norway Grants HU09-0095-A1-2016 entitled "Development of an innovative vermicompost technology for communal sewage sludge recycling". We thank John Koestel and Annette Dathe for the X-Ray tomography image acquisition and processing within the frame of the SOILSPACE Project, funded by the Research Council of Norway (project 240663).

\section{REFERENCES}

Abiven, S., Menasseri, S., Chenu, C., 2009. The effects of inorganic inputs over time on soil aggregate stability - A literate analysis. Soil Biology \& Biochemistry, 42, 1-12.

Adugna, G., 2016. A review on impact of compost on soil properties, water use and crop productivity. Academic Research Journal of Agricultural Science and Research, 4, 3, 93-104.

Alaoui, A., Rogger, M., Peth, S., Blöschl, G., 2018. Does soil compaction increase floods? A review. Journal of Hydrology, 557, 631-642.

Amézketa, E., Aragüés, R., Carranza, R., Urgel, B., 2003. Macro-and micro-aggregate stability of soils determined by a combination of wet-sieving and laser-ray diffraction. Spanish Journal of Agricultural Research, 1, 4, 83-94.

Angyal, A., 2019. The impact of methodology on soil water retention measurements. Master Thesis. Szent István University, Budapest, Hungary. (In Hungarian.)

Beck-Broichsitter, S., Fleige, H., Horn R., 2018. Compost quality and its function as a soil conditioner of recultivation layers - a critical review. International Agrophysics, 32, 1, $11-18$.

Bieganowski, A., Ryzak, M., Witowska-Walczak, B., 2010. Determination of soil aggregate disintegration dynamics using laser diffraction. Clay Minerals, 45, 23-34.

Borelli, P., Robinson, D.A., Panagos, P., Lugato, E., Yang, J.E., Alewell, C., Wuepper, D., Montanarella, L., Ballabio, C., 2020. Land use and climate change impacts on global soil erosion by water (2015-2070). Proceedings of the National Academy of Sciences of the USA, 117, 36, 21994-22001. https://www.pnas.org/cgi/doi/10.1073/pnas.2001403117
Bronick, C.J., Lal, R., 2005. Soil structure and management: a review. Geoderma, 124, 3-22.

Bucka, F.B., Kölbl, A., Uteau, D., Peth, S., Kögel-Knabner, I., 2019. Organic matter input determines structure development and aggregate formation in artifitial soils. Geoderma, $354,113881$.

Cahyono, P., Loekito, S., Wiharso, D, Afandi, Rahmat, A., Nishimura, N., Senge, M., 2020. Effects of compost on soil properties and yield of pineapple (Ananas comusus L. Merr.) on red acid soil, Lampung, Indonesia. International Journal of GEOMATE, 19, 76, 33-39.

Cambardella, C.A., Richard, T.L., Russell, A., 2003. Compost mineralization in soil as a function of composting process conditions. European Journal of Soil Biology, 39, 117-127.

De Pascale, S. Costa, L.D., Vallone, S., Barbieri, G., Maggio, A., 2011. Increasing water use efficiency in vegetable crop production: from plant to irrigation system efficiency. HortTechnology, 21, 3, 301-308.

Doube, M., Klosowski, M.M., Arganda-Carreras, I., Cordelieres, F.P., Dougherty, R.P., Jackson, J.S., Schmid, B., Hutchinson, J.R., Shefelbine, S.J., 2010. BoneJ: free and extensible bone image analysis in ImageJ. Bone, 47, 10761079. https://doi.org/10.1016/j.bone.2010.08.023.

Duong, T.T.T., Penfold, C., Marschner, P., 2012. Amending soils of different texture with six compost types: impact on soil nutrient availability, plant growth and nutrient uptake. Plant Soil, 354, 197-209.

ECN, 2017. Sustainable compost application in agriculture. ECN INFO Paper 09/2017. https://www.compostnetwork.info/ wordpress/wp-content/uploads/ECN_Info-Paper_09_2017 Longterm_use_of_Compost_in_Agriculture.pdf

Eijkelkamp, $\overline{2019}$. Sandbox for $\mathrm{p} \overline{\mathrm{F}}$-determination. User manual. M-0801E.

Farrell, M., Jones, D.L., 2009. Critical evaluation of municipal soil waste composting and potential compost markets. Bioresource Technology, 100, 4301-4310.

Foereid, B., Alvarenga, E., Szocs, J., Makadi, M., 2019. Ammonium sorbed to zeolite is partly available to wheat in the first growth cycle. Agronomy, 9, 3, 122.

Gaiotti F., Marcuzzo, P., Belfiore, N., Lovat L., Fornasier, F., Tomasi, D., 2017. Influence of compost addition on soil properties, root growth and vine performances of Vitis vinifera cv Cabernet sauvignon. Scientia Horticulturae, 255, 8895.

Gao, E.S., Liang, F., Yu, A., Li, B., Yang, L., 2010. Evaluation of stability and maturity during forced-aeration composting of chicken manure and sawdust at different $\mathrm{C} / \mathrm{N}$ ratios. Chemosphere, 78, 614-619.

Ghezzehei, 2012. Soil structure. In: Huang, P.M., Li, Y., Sumner, M.E. (Eds.): Handbook of Soil Sciences: Vol. 1 Properties and Processes. 2nd Ed. CRC Press, Boca Raton, Fla., pp. 1-17.

Haiti, K.M., Swarup, A., Mishra, B., Manna, M.C., Wanjari, R.H., Mandal, K.G., Misra, A.K., 2008. Impact of long-term application of fertilizer, manure and lime under intensive cropping on physical properties and organic carbon content of Alfisol. Geoderma, 148, 173-179.

Hashem, F.A., Abdrabbo, M.A.A., Abou-El-Hassan, S., AbulSoud, M.A., 2014. Maximizing water use efficiency via different organic mulches and irrigation levels. Research Journal of Agricultural and Biological Sciences, 10, 2, 109-117.

Haynes, R.J., Naidu, R., 1998. Influence of lime, fertilizer and manure application on soil matter content and soil physical conditions: a review. Nutrient Cycling in Agroecosystems, $51,123-137$. 
Hellner, Q., Koestel, J., Ulén, B., Larsbo, M., 2018. Effects of tillage and liming on macropore networks derived from Xray tomography images of a silty clay soil. Soil Use and Management, 34, 2, 197-205.

Holman, I.P, Hollis, J.M., Bramley, M.E., Thompson, T.R.E., 2003. The contribution of soil structural degradation to catchment flooding: a preliminary investigation of the 2000 floods in England and Wales. Hydrology and Earth System Sciences, 7, 5, 754-765.

Horel, Á., Barna, G., Makó, A., 2019. Soil physical properties affected by biochar addition at different plant phaenological phases. Part I. International Agrophysics, 33, 255-262.

Jamniczky, D., 2018. The effect of various compost materials on soil structure and water regime. Bachelor Thesis. Faculty of Food Science, Szent István University, Budapest, Hungary.

Jiang, Z., Zheng, H., Xing, B., 2021. Environmental life cycle assessment of wheat production using chemical fertilizer, manure compost, and biochar-amended manure compost strategies. Science of the Total Environment, 760, 143342.

Jindo, K., Chocano, C., Melgares de Aguilar, J., González, D., Hernandez, T., García, C., 2016. Impact of compost application during 5 years on crop production, soil microbial activity, carbon fraction, and humification process. Communications in Soil Science and Plant Analysis, 47, 16, 1907-1919.

Kemper, W.D, Rosenau, R.C., 1986. Aggregate stability and size distribution. In: Klute, A. (Ed.): Methods of Soil Analysis. Part 1. 2nd ed. Agron. Monogr. 9. American Society of Agronomy \& Soil Science Society of America, Madison, WI, pp. 383-409.

Klute, A., 1986. Water Retention: Laboratory methods. In: Klute, A. (Ed.): Methods of Soil Analysis. Part 1. 2nd ed. Agron. Monogr. 9. American Society of Agronomy \& Soil Science Society of America, Madison, WI, pp. 647-649.

Koestel, J., 2017. SoilJ: An ImageJ plugin for the semiautomatic processing of three-dimensional X-ray images of soil. Va$\begin{array}{llll}\text { dose Zone } \quad \text { Journal, } & 170062 .\end{array}$ https://doi.org/10.2136/vzj2017.03.0062

Koestel, J., Dathe, A., Skaggs, T.H., Klakegg, O., Ahmad, M.A., Babko, M., Gimenez D., Farkas, C., Nemes A., Jarvis, N., 2018. Estimating the permeability of naturally structured soil from percolation theory and pore space characteristics imaged by X-Ray. Water Resources Research, 54, 11, 92559263.

Kranz, C.N., McLaughlin, R.A., Johnson, A., Miller, G., Heitman, J.L., 2020. The effects of compost incorporation on soil physical properties in urban soils - A concise review. Journal of Environmental Management, 261, 110209.

Kubinova, R., Neumann, M., Kavka, P., 2021. Aggregate and pore size distribution of the soil sediment eroded on steep artificial slopes. Applied Sciences, 11, 10, 4427. https://doi.org/10.3390/app11104427

Lee, S.B., Lee, S.H., Jung, K.Y., Park K.D., Lee D., Kim P.J., 2009. Changes in soil organic carbon and its fractions in relation to soil physical properties in a long-term fertilized paddy. Soil Till. Res., 104, 2, 227-232.

Leelamanie, D.A.L., Manawardana, C.U., 2019. Soil hydrophysical properties as affected by solid waste compost amendments: seasonal and short-term effects in an Ultisol. Journal of Hydrology and Hydromechanics, 67, 3, 232-239.

Leroy, B.L.M., Herath, H.M.S.K., Sleutel, S., De Neve, S., Gabriels, D., Reheul, D., Moens, M., 2008. The quality of exogenous organic matter: short-term effects on soil physical properties and soil organic matter fractions. Soil Use and Management, 24, 139-147.

Martínez-Blanco, J., Lazcano, C., Christensen, T.H., Muñoz, P.,
Rieradevall, J., Møller, J., Antón, A., Boldrin, A., 2013. Compost benefits for agriculture evaluated by life cycle assessment. A review. Agronomy for Sustainable Development, 33, 4, 721-732.

Massah, J., Azadegan, B., 2016. Effect of chemical fertilizers on soil compaction and degradation. Agricultural Mechanization in Asia, Africa and Latin America, 47, 1, 44-50.

Maylavarapu, R.S., Zinati, G.M., 2009. Improvement of soil properties using compost for optimum parsley production in sandy soils. Scienta Horticulturae, 120, 426-430.

Miedema, R., 1997. Applications of micromorphology of relevance to agronomy. Advances in Agronomy, 59, 119-169.

Minitab, 2019. Minitab 19.2 Statistical Software. State College, PA, Minitab, Inc. (www.minitab.com)

Mukherjee, A., Lal, R., 2013. Biochar impacts on soil physical properties and greenhouse gas emission. Agronomy, 3, 2, 313-339.

Obalum, S.E., Chibuike, G.U., Peth, S., Ouyang, Y., 2017. Soil organic matter as sole indicator of soil degradation. Environmental Monitoring Assessment, 189, 176. DOI: 10.1007/s10661-017-5881-y

Or, D., Keller, T., Schlesinger, W.H., 2021. Natural and managed soil structure: On the fragile scaffolding for soil functioning. Soil and Tillage Research, 208, 104912.

Owen, D., Davis, A.P., Aydilek, A.H., 2021. Compost for permanent vegetation establishment and erosion control along highway embankments. Journal of Irrigation and Drainage Engineering, 147, 8. https://doi.org/10.1061/(ASCE)IR.19434774.0001587

Pierzynski, G., Brajendra (Eds.), 2017. Threats to Soils: Global Trends and Perspectives. A contribution from the Intergovernmental Technical Panel on Soils, Global Soil Partnership. Food and Agriculture Organization of the United Nations, $29 \mathrm{p}$.

Polakowski, C., Ryzak, M., Bieganowski, A., Sochan, A., Bartminki, P., 2015. The reason for incorrect measurements of the mass fraction ratios of fine and coarse material by laser diffraction. Soil Science Society America Journal, 79, 1, $30-36$.

Polprasert, 1989. Organic Waste Recycling. IWA Publishing.

Pravalie, R., 2021. Exploring the multiple land degradation pathways across the planet. Earth-Science Reviews, 220, 103689. https://doi.org/10.1016/j.earscirev.2021.103689

Rékási, M., Mazsu, N., Draskovtis, E., Bernhardt, B., Szabó, A., Rivier, P.-A., Farkas, C., Borsányi, B., Pirkó, B., Molnár, S., Kátay, G., Uzinger, N., 2019. Comparing the agrotechnical properties of compost and vermicomposts produced from municipal sewage sludge digestate. Bioresources Technology, 291, 121861.

Roba, T.B., 2018. Review on: The effect of mixing organic and inorganic fertilizer on productivity and soil fertility. Scientific Research, 5, 6, e4618.

Ros, M., Klammer, S., Knapp, B., Aichberger, K., Insam, H., 2006. Long-term effects of compost amendment of soil on functional and structural diversity and microbial activity. Soil Use and Management, 22, 209-218.

Ruggieri, L., Artola, A., Gea, T., Sanchez, A., 2008. Bio- degradation of animal fats in a co-composting process with wastewater sludge. Int. Biodeter. Biodegr., 62, 3, 297-303.

Schindelin, J., Arganda-Carreras, I., Frise, E., Kaynig, V., Longair, M., Pietzsch, T., Preibisch, S., Rueden, C., Saalfeld, S., Schmid, B., Tinevez, J.-Y., White, D.J., Hartenstein, V., Eliceiri, K., Tomancak, P., Cardona, A., 2012. Fiji: An open-source platform for biological-image analysis. Nature Methods, 9, 676-682. 
Schneider, C.A., Rasband, W.S., Eliceiri, K.W., 2012. NIH Image to ImageJ: 25 years of image analysis. Nature Methods, 9, 671-675. https://doi.org/10.1038/nmeth.2089

Singh, N., Kumar, S., Udawatta, R.P., Anderson, S.H., de Jonge, L.W., Katuwal, S., 2021. X-ray micro-computed tomography characterized soil pore network as influenced by long-term application of manure and fertilizer. Geoderma, 385,114872 .

Smith, P., House, J.I., Bustamante, M., Sobocká, J., Harper, R., Pan, G.X.,. West, P.C., Clark, J.M., Adhya, T., Rumpel, C., Paustian, K., Kuikman, P., Cotrufo, M.F., Elliott, J.A., McDowell, R., Griffiths, R.I., Asakawa, S., Bondeau, A., Jain, A.K., Meersmans, J., Pugh, T.A.M., 2016. Global change pressures on soils from land use and management. Global Change Biology, 22, 3, 1008-1028.

Sochan, A., Bieganowski, A., Ryzak, M., Dobrowolski, R., Bartminski, P., 2012. Comparison of soil texture determined by two dispersion units of Mastersizer 2000. International Agrophysics, 26, 99-102.

Stolte, J., Tesfai, M., Øygarden, L., Kværnø, S., Keizer, J., Verheijen, F., Panagos, P., Ballabio, C., Hessel, R. (Eds.), 2016. Soil threats in Europe. JRC Technical reports. EUR 27607 EN. DOI: $10.2788 / 828742$

Taina, I.A., Heck, R.J., Elliot, T.R., 2007. Application of X-ray computer tomography to soil science: A literature review. Can. J. Soil Sci., 88, 1, 1-19.

Tejada, M., Hernandez, M.T., Garcia, C., 2009. Soil restoration using composted plant residues: Effects on soil properties. Soil and Tillage Research, 102, 109-117.

Tejada, M., Gonzalez, J.L., 2006. Crushed cotton gin compost on soil biological properties and rice yield. European Journal of Agronomy, 25, 1, 22-29.

Tibbet, M., Fraser, T.D., Duddigan, S., 2020. Identifying potential threats to soil biodiversity. PeerJ, 8, e9271. https://peerj.com/articles/9271/

Tsai, R.Y., 1987. A versatile camera calibration technique for highaccuracy 3D machine vision metrology using off-theshelf TV cameras and lenses. IEEE Journal of Robotics and Automation, 3, 4, 323-344.

Turpin, N., ten Berge, H., Grignani, C., Guzmán, G., Vanderlinden, K., Steinmann, H-H., Siebielec, G., Spiegel, A., Perret, E., Ruysschaert, G., Laguna, A., Giráldez, J.V., Werner, M., Raschke, I., Zavattaro, L., Costamagna, C., Schlatter, N., Berthold, H., Sandén, T., Baumgarten, A., 2017. An assessment of policies affecting sustainable soil management in Europe and selected member states. Land Use Policy, 66, 241-249.

Unnisa, S.A., Rav, S.B., 2012. Sustainable Solid Waste Management. Apple Academic Press, Oakville, Canada.

Vageler, P.W.E., 1932. Der Kationen- und Wasserhaushalt des Mineralbodens. Springer, Berlin.

Virto, I., Imaz, M.J., Fernández-Ugalde, O., GartziaBengoetxea, N., Enrique, A., Bescansa, P., 2015. Soil degradation and soil quality in Western Europe: current situation and future perspectives. Sustainability, 7, 313-365.

Yang, Y., Wu, J., Mao, Y., Han, Q., He, F., 2013. Using computed tomography scanning to study soil pores under different soil structure improvement measures. Transactions of the Chinese Society of Agricultural Engineering, 29, 99-108.

Yang, Y., Wu, J., Zhao, S., Han, Q., Pan, X., He, F., Chen, C., 2018. Assessment of the responses of soil pore properties to combined soil structure amendments using X-ray computed tomography. Scientific Reports, 8, 695.

Yu, H., Ding, W., Chen, Z., Zhang, H, Luo, J., Bolan, N., 2015. Accumulation of organic $\mathrm{C}$ components in soil and aggregates. Scientific Reports, 5, 13804.

Waltner, I., Pásztor, L., Centeri, C., Takács, K., Pirkó, B., Koós, S., László, P., 2018. Evaluating the new soil erosion map of Hungary - a semiquantitative approach. Land Degradation and Development, 29, 4, 1295-1302.

Whelan A., Kechavarzi, C., Coulon F., Sakrabani, R., Lord, R., 2013. Influence of compost amendments on the hydraulic functioning of brownfield soils. Soil Use and Management, 29, 2, 260-270.

Wilke, B-M., 2005. Determination of chemical and physical soil properties. In: Margesin, R., Schinner, F. (Eds.): Manual of Soil Analyses - Monitoring and Assessing Soil Bioremediation. Springer-Verlag, Berlin Heidelberg, 2005.

Wortmann, C.S., Shapiro, C.A., 2008. The effects of manure application on soil aggregation. Nutrient Cycling in Agroecosystems, 80, 173-180.

WRB, 2014. World Reference Base for Soil Resources 2014. World Soil Resources Reports No. 106. Rome, 192 p.

Zhao, G., Mu, X., Jiao, J., Gao, P., Sun, W., Li, E., Wei, Y., Huang, J., 2018. Assessing response of sediment load variation in climate change and human activities with six different approaches. Science of the Total Environment, 639, 773-784.

Received 6 July 2021 Accepted 22 December 2021 